REVISTA

dela

CEPA

NUMERO EO

ACOBTO 1993

SANTIAGO DE CHILE

ANIBAL PINTO

Director

EUGENIO LAHERA

Secretario Técnico

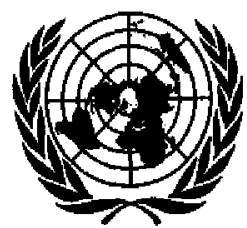

NACIONES UNIDAS 
Jacobo Schatan

La Integración reglonal en los años noventa

Gert Rosenthal

El resurgImiento de la Integración y el legado de Prebisch

José Manuel Salazar

La liberallzación comerclal en América Latına

Manuel Agosin y Ricardo Ffrench-Davis

Crecimiento, crisls y viraje estratéglco

Joseph Ramos

Falla del mercado y política tecnológlca

Jorge M. Katz

Crisis monetarla, dolarlzación y tipo de camblo

Paulo Nogueira Batista Jr.

El financiamlento en los procesos de descentralización

Dolores Marta Rufián Lizana

Migración intrarregional de mano de obra calificada

Jorge Martinez

Clencias sociales y realidad soclal en Centroamérlca

Andrés Pérez

Formación histórlca de la estratificación soclal en América Latina

Enzo Falefto

Estructura socioeconómica y comportamlento colectivo

Rodrigo Baño

Clasiflcaclón por autores y temática de los artículos publicados

en la Revista de la CEPAL, del número 1 al 50

Orlentaciones para los colaboradores de la Revista de la CEPAL 


\section{El financiamiento en los procesos de descentralización}

\section{Dolores Maria Ruflán Llzana}

Experta de la Agencia Espa* nola de Cooperación Internacional en mision en el Instituto Latinoamericano de Planificación Económica y Social (ILPES).
La financiación de las administraciones subnacionales de un Estado, tanto en páses federales como unitarios, es un instrumento para la descentralización; primero, cada Estado ha de decidir cuál es la competencia que corresponde a cada una de esas administraciones, y después deberá diseñar el mecanismo adecuado de financiación. La falta de adecuación, prolongada en el tiempo, entre la autonomía fiscal y la administrativa, puede llevar a que las administraciones subnacionales fracasen, al ir perdiendo poder de decisión en el ámbito de su competencia. Las administraciones subnacionales tienen pocas posibilidades de financiarse completamente con recursos propios. En la realidad, utilizan un conjunto de fuentes de financiamiento - rendimientos de tributos propios, participación en los rendimientos del sistema impositivo del Estado central y subvenciones procedentes del gobierno central- en diferentes proporciones. No obstante, alcanzan un alto grado de madurez fiscal cuando son poco dependientes, desde el punto de vista financiero, de la administración central. La independencia sólo es posible cuando la administración subnacional se financia con recursos propios o con recursos transferidos no condicionados y predecibles. La mayor dependencia, por el contrario, es la que resulta de la financiación basada en transferencias condicionadas. El artículo se ha ilustrado con algunos ejemplos acerca de cómo operan estas fuentes de financiación en algunos países de América Latina. 
I

\section{Introducción}

La descentralización es un proceso de transferencia de competencias desde la administración central de un Estado hacia las administraciones subnacionales: estatales y municipales en los países federales, y regionales y comunales en los países unitarios. De este modo, entenderemos que un Estado está descentralizado cuando sus administraciones territoriales tienen un conjunto de competencias significativo.

Pero para que las administraciones subnacionales puedan ejercer efectivamente las competencias transferidas necesitarán disponer de los recursos necesarios. La financiación de los estados federados, regiones y municipios, por consiguiente, es un tema fundamental en el estudio de la descentralización: la mayor parte de las reformas de los Estados latinoamericanos, iniciadas en la última década, ven en ella no sólo un refuerzo de su democratización, sino también un elemento de eficiencia en la asignación de las competencias y los recursos dentro del país.

Los procesos de descentralización no pueden ser concebidos sin considerar los recursos financieros adecuados a las unidades subnacionales de gobierno, so pena de su absoluto fracaso. El tema no es trivial, porque aunque la descentralización ha sido justificada por las expectativas de reducir los gastos del gobierno central o lograr una mayor eficacia en la asignación de recursos del sector público, "en la práctica, sin embargo, el resultado inmediato de los programas de descentralización en Latinoamérica (por ejemplo Brasil, Colombia, Ecuador, Guatemala y Venezuela) ha sido el incremento de los gastos del gobierno central debido a una combinación de factores: las exigencias legales respecto a las fórmulas de transferencias intergubernamentales de recursos; las consecuencias no esperadas de las políticas de distribución de ingresos, que han significado un desestímulo al incremento de ingresos por parte de las unidades subnacionales; el condicionamiento por parte de las autoridades centrales sobre el uso de recursos en funciones específicas, $y$, en forma más crucial, las limitaciones impuestas sobre las unidades subnacionales de gobierno para que aumenten su base de ingresos" (Morgan, 1991, p. 10). Es evidente, entonces, que si no se presta una mayor atención a los problemas financieros, el centralismo tributario puede llevar a una recentralización administrativa.
En suma, el financiamiento de la descentralización debe ser eficiente en la asignación de competencias, de manera que las distintas administraciones subnacionales dispongan de recursos suficientes para asumirlas, en un marco de autonomía de decisión y de equidad para con los distintos espacios territoriales que componen la nación. ${ }^{1}$

El tema es complejo no sólo por las tensiones inherentes a la organización de un Estado con varios niveles de gobierno y la consiguiente dificultad de asignación de tareas y funciones dentro de él, sino además porque el problema de la financiación trae consigo tensiones adicionales, por la diversidad de objetivos que se persiguen, la variada gama de instrumentos de que se dispone y las complicadas relaciones y yuxtaposiciones entre unos y otros (Giménez, 1979).

La sola asignación eficiente de competencias es ya de por sí un objetivo enormemente complejo, pues las administraciones centrales suelen ser más eficientes en algunas funciones y las descentralizadas en otras: por ejemplo, a nivel central suele haber más eficiencia en la administración de ingresos, mientras que la movilización de recursos suele ser mejor a nivel local.

En cuanto al objetivo de suficiencia presupuestaria, las nuevas competencias transferidas a las administraciones subnacionales elevan en ellas las necesidades de gasto, que han de ser equilibradas con ingresos suficientes para hacerles frente. Esto genera múltiples tensiones. En efecto, si ya es difícil equilibrar el presupuesto del Estado, en situaciones de restricción de recursos como las que actualmente se observan en América Latina, un proceso de descentralización puede desequilibrarlo con facilidad porque normalmente, y sobre todo al comienzo, la administración central ha de seguir encargándose al menos parcialmente de las competencias transferidas, lo que siempre acarrea alguna ineficiencia.

Los recursos para financiar las competencias transferidas pueden provenir de ingresos tributarios propios de las administraciones subnacionales o de

\footnotetext{
1 Respecto a la actualidad de estos conceptos, véase Castells, 1991.
} 
transferencias del Estado. Los tributos propios marcan la autonomía financiera de dichas administraciones, mientras que las transferencias del Estado, sobre todo si están condicionadas por la administración central, marcan su grado de dependencia. Las tensiones entre autonomía y dependencia suelen agravarse cuando hay irresponsabilidad fiscal de las administraciones subnacionales, lo que genera importantes contradicciones entre los objetivos macroeconómicos estatales y los objetivos fínancieros de las regiones y municipios. Si a ello se suman problemas derivados de las políticas de endeudamiento y déficit de las distintas administraciones subnacionales, las tensiones con la administración central recrudecen.

Por último, frente al objetivo de equidad, las profundas diferencias de ingreso entre administraciones del mismo rango pueden reflejarse en diferencias en la prestación de servicios dentro del mismo Estado, lo que hace necesario un mecanismo de igualación o nivelacion de ingresos, cuyo establecimiento genera siempre tensiones interterritoriales. Debe considerarse además la fínanciación de las medidas de reequilibrio interregional orientadas a nivelar el desarrollo de los distintos espacios territoriales, para lo cual éstos necesitan de una política distinta.

\section{II}

\section{El financiamiento de la descentralización:}

\section{una cuestión instrumental}

Con todo, la financiación de las administraciones subnacionales es un tema secundario $\longrightarrow$ al menos instrumental- en las decisiones sobre el proceso de descentralización. Cada país debe decidir cuál es el grado deseable de centralización y descentralización de sus servicios y determinar después el mecanismo de financiación adecuado. La decisión sobre el proceso de descentralización es de carácter político y ha de tener un reflejo constitucional y traducirse después en un esquema de competencias dentro de los niveles de gobiemo. Habrá que establecer primero cuál es el quantum de competencias de cada nivel administrativo, y sólo después analizar cómo han de financiarse esas competencias.

Cabe tener en cuenta, no obstante, que la correspondencia entre descentralización administrativa de funciones y autonomía fiscal no es exacta, al menos en los inicios de los procesos. En efecto, un alto grado de descentralización administrativa significa que los entes regionales o municipales descentralizados tienen autonomía para decidir sobre las competencias transferidas, en tanto que un alto grado de autonomía fiscal implica que los entes descentralizados tienen autonomía para decidir acerca de las exacciones tributarias que imponen en su territorio. Sin embargo, no existe correspondencia entre una y otra autonomía porque los servicios descentralizados suelen financiarse, sobre todo en los países unitarios, mayoritariamente con transferencias de la administración central, y en un porcentaje muy bajo con tributos propios. La escasa capacidad de los entes descentralizados para generar tributos propios no es en principio un obstáculo para transferir mayores competencias. Sin embargo, si la falta de sincronización que es explicable al inicio del proceso persiste, puede poner en peligro la viabilidad de éste (Castells,1991).

La descentralización de competencias administrativas puede ser medida en función de las efectivamente transferidas a los gobiemos subnacionales; esta transferencia se reflejará en la participación del gasto público de los gobiernos subnacionales en el de la administración central. Sin embargo, ese porcentaje de participación no tiene en cuenta el origen de los ingresos gastados por los gobiernos subnacionales. El concepto de descentralización fiscal es el que da cuenta de ello con distintos tipos de mediciones, que pueden dar lugar a diferentes tipos de autonomía.

Una primera aproximación al origen de los ingresos es la que atiende al ente que establecio el tributo. Así, se dice que un modelo fínanciero es centralista cuando las exacciones sobre los ciudadanos las establece fundamentalmente la hacienda central, mientras que los ingresos de las otras haciendas corresponden en su mayor parte a transferencias procedentes de aquélla. Por el contrario, un modelo financiero es descentralista cuando cada hacienda establece sus propias exacciones, de las cuales deriva la mayor parte de sus ingresos, sin perjuicio de recibir las 
transferencias redistributivas que efectúa la administración central (Sevilla Segura, 1991).

Este criterio no se utiliza siempre; en ocasiones se dice que la descentralización fiscal está determinada por la autonomía de gasto de que goza la administración subnacional y que ésta tendrá dicha autonomía no solamente en la medida en que establezca tributos propios sino también en la medida en que reciba del Estado transferencias automáticas y predecibles, como son las procedentes de las participaciones en los ingresos del Estado. Esto es lo que explica, por ejemplo, que países como Argentina sean incluidos entre aquellos con alto grado de descentralización fiscal, a pesar de que el sistema de financiación federal argentino está basado en su participación en los impuestos de la administración central (Banco Mundial, 1990).

El tema de la financiación, pese a su carácter instrumental, suele añadir una contradicción al proceso de descentralización administrativa porque en la práctica, y sobre todo al inicio del proceso, supone un mayor gasto en el conjunto de las administraciones aun cuando no aumente la cantidad o calidad del servicio prestado.

Un reciente estudio preparado por el Banco
Mundial para nueve países latinoamericanos (Campbell, 1991) muestra que la mayoría de las estrategias de descentralización han tenido costos netos adicionales significativos (en particular en Colombia, Brasil, Guatemala y Venezuela). Si bien en parte esto puede deberse a que la reestructuración de competencias lleva a la vez a introducir mejoras imprescindibles en la calidad del servicio, ${ }^{2}$ en la mayoría de los casos no ha habido una reducción real significativa de las responsabilidades de gasto a nivel central. $Y$ aunque algunos costos pueden ser transitorios, la experiencia indica que la reducción del gasto central se materializa muy lentamente y que no es total. Solamente en Chile, Ecuador y Argentina se ha utilizado la reforma financiera intergubernamental como instrumento de restricción del presupuesto nacional.

Lo anterior puede hacer que se desvirtúe el proceso de descentralización y que el Estado se recentralice y se traspasen de nuevo las competencias al nivel central, simplemente porque no se resolvieron correctamente los problemas financieros. En estos casos la financiación deja de ser un tema instrumental de la descentralización.

\section{III}

\section{La asignación de competencias y de}

\section{recursos a los diferentes niveles de}

\section{administración y gobierno}

La asignación de competencias a los diferentes niveles de gobierno es un tema complejo, que ha sido detenidamente estudiado desde el ángulo del análisis económico. Aquí sólo haremos breves referencias a él, con el objeto de estudiar las cuestiones relacionadas con la financiación. Para estos fines vamos a admitir como válido el tradicional enfoque musgraviano que diferencia tres funciones dentro del sector público -asignativa, redistributiva y estabilizadoray postula que sólo la función asignativa, consistente fundamentalmente en la provisión de bienes públicos,

\footnotetext{
${ }^{2}$ Algo así ocurrió por ejemplo en Brasil cuando se transfirieron a los estados y a los municipios los servicios de salud que estaban en manos del Estado federal: esos servicios estaban en condiciones absolutamente deterioradas y se necesitaron importantes inversiones para poder seguir prestándolos. Al respecto véase Brakarz, 1991.
}

debe ser desempeñada por todos los niveles de gobierno. ${ }^{3}$ Aparece así lo que se ha denominado "teorema de la descentralización", según el cual la descentralización en la provisión de bienes públicos permite diversificar la oferta en función de las preferencias de los ciudadanos, tomando en consideración la existencia de demandas diferenciadas.

Dicho teorema tiene un fundamento económico muy importante, según el cual la prestación de servicios óptima sólo puede alcanzarse de manera descentralizada; pero también un importante componente político, que diferencia la descentralización de la desconcentración. La ventaja de la descentralización re-

\footnotetext{
${ }^{3}$ El análisis económico de Musgrave (1991), sin haber perdido vigencia, puede ser hoy cuestionado desde algunos puntos de vista.
} 
side en que introduce el mecanismo de elecciones para conocer las preferencias de los ciudadanos.

Del análisis económico de las funciones surge la otra aseveración importante para la financiación: que, en principio, no corresponde a las administraciones inferiores el establecimiento de tributos de carácter redistributivo o estabilizador.

Pero la asignación de competencias a los diferentes niveles de gobierno no es un proceso teorico por el cual se asigna la función al nivel más eficiente para llevarla a cabo. Por el contrario, se trata de un proceso muy complejo. En primer lugar, la descentralización requiere la decisión política de iniciar el proceso o de continuarlo dentro de un Estado que ya estaba funcionando de manera más o menos descentralizada. Por otra parte, no todos los niveles subnacionales de la misma categoría están preparados para cumplir las mismas funciones. Por último, la asignación de competencias verticales es prácticamente imposible, y en la mayor parte de los servicios que presta un Estado deben concurrir varios niveles de administración.

En América Latina la descentralización es hoy objeto de debate en casi todos los países; pero los procesos de descentralización mismos son muy distintos entre sí.

En los países federales el tema está en boga a pesar de que, en principio, ellos ya estarían descentralizados. En esos países el proceso apunta fundamentalmente a transferir a las administraciones estaduales más competencias de las que ya tenían y que van a ejercer de manera exclusiva; a establecer sistemas de competencias concurrentes, y a fijar mecanismos de coordinación con el Estado central y de los distintos estados entre sí. Aunque los procesos mismos y las soluciones políticas difieren mucho de un país a otro, en general los países federales latinoamericanos responden a la tradición centralista continental más que al modelo federalista norteamericano. Algunos países, como Venezuela y Brasil, actualmente están analizando y llevando a cabo procesos de mayor descentralización porque su sociedad política y civil ha acordado que los gobiernos estaduales y municipales provean más servicios en perjuicio de la administración central (Shah, 1990; CLAD, 1991). En México, por el contrario, la sociedad muestra una actitud más proclive a que sea el gobierno central el que proporcione los servicios (CEPAL, 1985).

Si el grado de descentralización de competencias se mide a través del gasto realizado por los gobiernos subnacionales, lo que decimos es evidente, pues mientras en México dicho gasto es inferior al $20 \%$, en países como Argentina y Brasil se aproxima al 30\% del total. (Banco Mundial, 1988, promedios de 1974-1986).

En algunos países unitarios se pretende primero crear regiones como entes descentralizados, para transferir después las competencias (Perú y Guatemala).

Por último, en otro grupo de países lo que se busca con la descentralización es reforzar la administración local a nivel de municipio (que ya era tạnbién un ente descentralizado) y transferirle nuevas competencias (Colombia y Chile).

Los problemas de financiación en todos estos casos son distintos. Cuando al inicio del proceso hay ya entes descentralizados, aunque tengan escasas competencias y reducida capacidad de gasto, éstos tienen ya organizada su propia hacienda, sobre la cual puede basarse un nuevo sistema de financiación. Una relativa madurez en el proceso de descentralización administrativa, como la que debiera darse en los paises federales, debería originar a su vez una apertura del proceso de descentralización fiscal; se iría sustituyendo paulatinamente la financiación basada en transferencias de recursos del Estado central a los estados subnacionales, por exacciones impuestas por estos últimos, los que administrarían autónomamente sus ingresos y se responsabilizarían de ello ante sus ciudadanos. Este era al parecer uno de los objetivos de la reforma del sistema fiscal en Brasil, donde al discutirse el tema de la financiación no ha estado en juego solamente la suficiencia financiera de los estados subnacionales para hacer frente a sus gastos, sino también la autonomía de estos últimos para establecerla.

Surge no obstante una dificultad adicional en el proceso de descentralización: las finanzas subnacionales suelen estar en una situación deteriorada incluso antes de asumir las nuevas competencias propuestas, lo que puede tornar reacios al proceso a los gobiernos estaduales, regionales y locales. Por este motivo, en lugar de aplicar una política de estímulo a la transferencia de competencias basada en criterios técnicos, los gobiernos centrales suelen intentar hacer transferencias de recursos sin haber acordado previamente la transferencia de competencias y sin exigirlas, lo que puede desembocar en descalabros financieros.

Por el contrario, cuando se crean nuevos entes descentralizados es preciso crear una hacienda propia. Por otra parte, es evidente que los problemas de financiamiento que se plantean los estados federados 
o las regiones son distintos de aquellos que surgen en los municipios.

La asignación de competencias se hace más compleja por el hecho de que los estados, regiones y municipios del país por lo general carecen de la capacidad de gestión necesaria para asumir a un tiempo las competencias transferidas.

En principio, los sistemas de transferencia son de tres tipos:

i) La transferencia en bloque a todos los niveles territoriales, lo que en principio evitaría la desorganización financiera de la administración central que, al transferir la competencia, traspasaría al mismo tiempo los recursos para administrar el servicio; no obstante, es posible que se generen muchos problemas de gestión en la nueva administración descentralizada.

ii) El sistema de transferencias fraccionadas, por el cual son los entes descentralizados los que han de solicitar el traspaso de la competencia del nivel central cuando estiman que su capacidad de gestión es suficiente para la administración del servicio; el sistema es ventajoso para los entes subnacionales, pero origina desequilibrios de todo tipo en el nivel central $y$, sobre todo, el gasto se incrementa.

iii) Por último, sistemas de transferencia mixtos en los cuales se da preferencia a la iniciativa de los gobiernos subnacionales, de manera que cuando ellos solicitan la competencia, ésta se transfiere inmediatamente; sin embargo, pasado cierto tiempo, el gobierno central puede decidir una transferencia en bloque si la competencia no ha sido solicitada. En sus prime- ros momentos, este sistema produce desestabilización y deseconomías de escala, pero asegura un mejor funcionamiento futuro. En general, la mayor parte de los países han utilizado variaciones de él.

Conviene por último referirse a las competencias compartidas o concurrentes. Cuando hay varios niveles de gobierno es imposible establecer una absoluta separación de competencias porque todas las funciones se desarrollan sobre un mismo territorio, siendo el conflicto consustancial a la descentralización. Aunque parezca paradójico, los estudios sobre descentralización indican que la minimización del conflicto es más factible cuando la distribución de competencias no es rígida y se establecen competencias concurrentes entre las distintas administraciones, siendo el procedimiento de negociación y concertación fundamental para llevar a cabo la prestación del servicio. No obstante, es preciso que, aunque las competencias no sean rígidas, la ley haga una delimitación precisa de las responsabilidades de las diferentes administraciones. En este contexto se requerirá madurez en el ámbito administrativo y fiscal para resolver los conflictos.

Por lo expuesto, puede decirse que a una determinada situación de las competencias en un conjunto de administraciones debe responder un esquema de financiamiento que permita que los entes descentralizados posean los recursos suficientes para hacer frente a la prestación de los servicios cuya responsabilidad se les ha conferido. No existe, sin embargo, un modelo de financiamiento general que sea más o menos común a los países federales ni a los unitarios.

\section{IV}

\section{Los recursos de las administraciones}

\section{descentralizadas}

Los recursos con que se financian los gobiernos subnacionales pueden provenir de diversas fuentes, las que caen básicamente en tres categorías generales: i) tributos propios; ii) participación en los rendimientos del sistema impositivo del Estado central, y iii) subvenciones del gobierno central.

En mayor o menor medida, los entes descentralizados utilizan los tres tipos de fuentes. No obstante, por lo general la financiación derivada de un sistema de tributación propio es siempre muy reducida, de manera que los entes descentralizados obtienen el grueso de sus recursos de su participación en los rendimientos del gobierno central o de las subvenciones que él les asigne. Esto es lo que se conoce como dependencia financiera: los gobiernos subnacionales dependen del Estado central para poder financiar los servicios que prestan. El grado de dependencia financiera estará en función del instrumento utilizado para la financiación, que puede restringir o no la autonomía en el gasto de los entes subnaciona- 
les, y es mayor en el caso de las subvenciones condicionadas.

Algunos estudios solamente excluyen de los ingresos de los gobiernos subnacionales las transferencias condicionales o las transferencias no automáticas. En realidad, el mayor o menor grado de dependencia no está ligado a determinados sistemas de financiamiento de los entes descentralizados. Los gobiernos subnacionales no tienen por qué ser contrarios a esa dependencia, y pueden preferir ese sistema de financiación, aun a riesgo de perder autonomía, bien por motivos económicos (consideraciones de eficiencia unidas a la fácil movilidad de bienes y personas que pueden derivar de un trato fiscal diferenciado), bien por motivos políticos (cuestiones relativas a la asunción del costo de la impopularidad que acarrean algunas decisiones fiscales). En otro sentido, la dependencia puede significar la comprobación de la incapacidad de los gobiernos subnacionales de autofinanciarse (Suárez Pandello, 1988, pp. 79 y 80).

El que los entes subnacionales dependan del go- bierno central para financiar los servicios descentralizados tiene dos consecuencias importantes (Sevilla Segura, 1991):

i) Los gobiernos subcentrales pueden caer fácilmente en la irresponsabilidad fiscal, ya que obtienen sus recursos sin tener que soportar el costo político que implica imponer tributos a sus propios votantes. Como dicho costo político sólo recae sobre la administración central, los gobiernos subcentrales tienden a presionar a la administración central para lograr recursos.

ii) Los gobiernos centrales, por su parte, tratan entonces de que la dependencia sea de alto grado e imponen condiciones a los gobiernos subcentrales para entregarles los recursos. La subvención condicionada aparece así como un importante ingreso de los entes descentralizados que restringe la autonomía de la respectiva administración subnacional.

Analicemos ahora más detenidamente los tipos de recursos señalados y veamos algunos ejemplos de su utilización en América Latina.

\section{V}

\section{La autonomía fiscal a través}

\section{de ingresos propios}

Aunque ya advertimos que la descentralización administrativa y la descentralización fiscal no se corresponden, al menos en las etapas de inicio de los procesos descentralizadores, es un hecho que la propia dinámica del proceso exige que la descentralización se financie cada ve $z$ más con tributos establecidos y recaudados en el territorio subnacional correspondiente, como única manera de resolver de manera permanente el problema de la financiación tanto de los entes descentralizados como del gobierno central: ${ }^{4}$ las necesidades de los gobiemos subnacionales crecen a un ritmo tan rápido que necesariamente comprometen el propio presupuesto central y su capacidad para seguir

\footnotetext{
${ }^{4}$ Buena prueba de ello es la crisis actual en que se encuentra el sistema de financiación del Estado descentralizado español. En efecto, aunque ha sido muy exitoso en lo que se refiere a la transferencia de competencias a las Comunidades Autónomas, los problemas de financiación generados sólo pueden resolverse aumentando el peso de los ingresos tributarios propios. Sobre la discusín actual véanse Castells (1991) y Sevilla Segura (1991).
}

prestando los servicios que le son asignados y las funciones de estabilización y redistribución. Por 1o demás, la autonomía de un ente descentralizado se ve seriamente menoscabada si el ente que la financia impone condiciones. Sin embargo, no es fácil establecer un sistema de imposición propio porque éste exige una madurez fiscal en todo el territorio que difícilmente se da en América Latina, y porque además determinados tributos quedan prácticamente fuera del alcance de los entes subnacionales, por razones de análisis económico.

Aunque los ingresos propios pueden ser clasificados de varias formas, para los efectos de nuestro análisis consideraremos como tales aquellos tributos cuyos rendimientos perciben los gobiernos correspondientes según estrictos criterios de territorialidad: es decir, cuyos rendimientos corresponden a un gobierno que tiene jurisdicción en el lugar donde se han recaudado. Entre ellos se incluyen aquellos tributos en los que el ente descentralizado goza de manera 
exclusiva de la titularidad impositiva; aquéllos en los que goza de titularidad compartida en virtud de recargos o fuentes que permiten la doble imposición y asimismo, la participación, por razón del territorio, en los impuestos estatales (tax sharing). Por el contrario, la participación en los impuestos estatales por conceptos distintos de la territorialidad genera lo que denominaremos subvenciones o transferencias generales (revenue sharing). No obstante, hay que advertir que la terminología no es igual en todos los países ni en todos los autores que escriben sobre el tema y que a veces las participaciones en impuestos, de cualquier clase que sean, son consideradas transferencias o subvenciones. En sentido inverso, para los efectos de la autonomía o dependencia del gobierno subnacional, en algunos documentos las participaciones en impuestos se consideran como ingresos propios. El tema tiene particular importancia en América Latina, donde los entes subnacionales de los países federales se financian mayoritariamente con dichas participaciones.

Cabe hacer una última advertencia respecto de aquellos tributos cuya titularidad posee la administración central pero que son recaudados por otras administraciones. Para estos efectos, dichos tributos se considerarán como centrales en la medida en que la titularidad legislativa corresponda al Estado central; no obstante, la participación de los gobiernos subnacionales en las tareas de gestión puede ser un factor de importancia para acrecentar su propia responsabilidad fiscal y permitir incluso niveles más altos de recaudación.

$\mathrm{El}$ análisis económico proporciona criterios técnicos para atribuir las distintas fuentes de tributación a los distintos niveles de gobierno.

Musgrave (1991) destaca los siguientes criterios: i) los niveles medios y bajos deberían gravar las bases de baja movilidad interjurisdiccional; ii) los impuestos personales progresivos deberían ser usados por aquellas jurisdicciones en las que se pudiera aplicar más eficientemente una base global; iii) la imposición progresiva de objetivos distributivos debería ser central; iv) los impuestos apropiados para la política de estabilización deberían ser centrales y los de los niveles inferiores, estables cíclicamente; v) las bases distribuidas de manera altamente desigual entre subjurisdicciones deberían ser usadas centralmente; vi) los impuestos aplicados según el principio de beneficio y las tasas sobre usuarios son apropiados a todos los niveles. De esta manera, se asigna al nivel central el impuesto integrado sobre la renta, sobre el gasto, sobre los recursos naturales y las tasas; al nivel medio el impuesto sobre la renta de los residentes y de los no residentes, el impuesto en destino sobre las ventas y sobre los recursos naturales y las tasas, y al nivel local el impuesto sobre la propiedad, y sobre las nóminas y las tasas. Con posterioridad Mattews añade la necesidad de establecer fórmulas de participación impositiva para contrarrestar el desequilibrio fiscal entre niveles de gobierno (véase Castells, 1988).

$\mathrm{El}$ establecimiento de tributos propios por parte de los entes descentralizados puede hacerse de dos formas, que de ninguna manera son incompatibles entre sí:

i) Separando las distintas fuentes de ingreso. De esta manera se reservan unas para la administración central y otras para las administraciones descentralizadas. Este sistema, que se conoce como de haciendas complementarias, plantea un problema: las buenas fuentes de ingreso fiscal son limitadas (renta y ventas, fundamentalmente), y si éstas son reservadas a la administración central, como sugiere el análisis económico, los entes descentralizados no tendrán garantizada su autonomía. Un buen ejemplo de cómo se han distribuido estas fuentes de ingreso es el que proporciona la Constitución brasileña del 5 de octubre de 1988, que trata efectivamente de garantizar un amplio margen de autonomía fiscal a los entes descentralizados (artículos 153 a 156): a la Unión Federal corresponden los impuestos sobre las importaciones; las exportaciones; la renta; los productos industriales; las operaciones de crédito, cambios y seguro; la transmisión de títulos o valores mobiliarios, y también los que recaen en la propiedad territorial rural y las grandes fortunas; a los estados federados y al Distrito Federal corresponden los impuestos que recaen en las sucesiones y donaciones, la propiedad de vehículos automotores, la circulación de mercancías y la prestación de servicios y a los municipios corresponden los impuestos que recaen en la propiedad predial y territorial urbana, las transmisiones de inmuebles y los derechos reales sobre los mismos, las ventas al por menor de combustibles y ciertos servicios. En esta separación de las fuentes de ingreso hay que destacar que se ha reservado a la Unión Federal un impuesto de muy alta recaudación, como es el impuesto sobre la renta, pero también se ha reservado a los estados federados y al Distrito Federal otro impuesto muy elástico, como es el que grava la circulación de mercancías y la prestación de servicios, lo que en principio permite augurar cierta autonomía fiscal a estos últimos. Los municipios contarán con impuestos tradi- 
cionalmente locales, de escasa recaudación, y con tasas y contribuciones especiales que atienden al principio del beneficio.

ii) Estableciendo cada ente autónomo sus propios tributos mediante haciendas en paralelo. Esto puede llevar a la existencia de impuestos en duplicado: por ejemplo, un impuesto sobre la renta establecido por el Estado y otro distinto establecido por el ente subnacional. Aunque la doble imposición no es de por si objetable, puede generar problemas cuando se aplica sin considerar sus efectos agregados en el conjunto del sector público y en el sector privado. Además, puede crear complicaciones para los ciudadanos ante la posible profusión de exacciones del mismo tipo, por lo que los países que las aplican tienden a reducirlos (Los casos de doble imposición se han reducido apreciablemente en Estados Unidos, donde todavía existen). No obstante, el sistema de haciendas en paralelo puede ser de simple aplicación cuando se establece un sistema estructurado en torno a la hacienda central y se permite después que los entes autónomos establezcan recargos sobre los tributos centrales. Esta segunda forma de tributo propio no es incompatible con la anterior. El sistema de financiación puede prever que algunas fuentes de imposición queden reservadas a un determinado ente y que sobre otras puedan establecer tributos varios entes. Así, por ejemplo, la Constitución de Brasil dispone que los estados federados y el Distrito Federal, además de los impuestos que pueden establecer por corresponderles la fuente de ingreso, pueden institucionalizar un recargo sobre el impuesto a la renta de la Unión. Un sistema parecido se propone actualmente en Venezuela, a través de sobretasas a tributos nacionales como el impuesto a la renta o los impuestos al consumo, a las transacciones o al valor agregado. Se trataría, en este último caso, de unos puntos adicionales que los gobernadores podrían incorporar al porcentaje del impuesto establecido por la nación (De la Cruz, 1989).

Las dos formas de tributos propios descritas permiten a los entes autonomos un alto grado de autonomía política y de responsabilidad fiscal, ya que ellos deben decidir la exacción que imponen a sus ciudadanos. El principio de autonomía exige que la cuantía de dicha exacción sea decidida por cada ente descentralizado en particular, aunque a veces lo es a nivel nacional. Por ejemplo, el impuesto al valor agregado (IVA) en Brasil es administrado por un Consejo al que pertenecen todos los estados y que debe aprobar cualquier cambio en la exacción.

Los países unitarios, pero en los que las regiones se han convertido en entes autónomos, también pueden prever la existencia de tributos propios de las regiones. En este sentido, la Ley de Bases de Regionalización de Perú (Ley No 24650 del 19 de marzo de 1987) prevé entre los recursos de los gobiernos regionales "los tributos que creen al amparo de competencias legislativas delegadas". Del mismo modo, el Proyecto de Ley de Organización de Gobiernos Departamentales de Bolivia plantea la existencia de recursos propios de cada región.

En los países en los que no se ha previsto que la region sea un ente descentralizado (sea o no el país un estado federal) se prevé no obstante para los municipios la existencia de algunos recursos propios, cuya recaudación no es muy importante por estar basada fundamentalmente en tasas y en impuestos a la propiedad territorial. Pero cuando se trata de acelerar el proceso de descentralización, suele darse impulso a este tipo de ingresos municipales. En el proceso colombiano de descentralización municipal, por ejemplo, el Decreto 1333 (04/1986) actualiza el Código de Régimen Municipal, donde por disposiciones legales (ley 14 de 1983) se autoriza a los municipios para que fortalezcan, entre otros, los impuestos predial, de industria, de comercio, de avisos y tableros, de circulación y tránsito, de parques y arborización, de espectáculos, de casinos y otros. Más recientemente, la ley $44(12 / 1990)$ y los nuevos preceptos constitucionales (Constitución Política de 1991) en materia de régimen de los entes territoriales, vienen promoviendo la autonomía tributaria y el fortalecimiento de la base económica regional y local.

Dentro de los ingresos propios hemos incluido también una tercera categoría, que es la de la participación en ingresos centrales según criterios de territorialidad, es decir, en función del monto real del ingreso recaudado en cada ente autónomo. La recaudación $y$, en general, la gestión del tributo pueden ser efectuadas directamente por la administración central o bien por las administraciones subnacionales. En rigor, se trata de transferencias desde el Estado central a los entes autónomos. La titularidad legislativa del impuesto corresponde a la administración central, que decide la base sobre la cual se aplica el tributo y el tipo de gravamen (a diferencia de los casos anteriores), pero todo o parte de lo recaudado por el impuesto es después distribuido en proporción a lo efectivamente percibido en el territorio de que se trate, sin que la cuantía sea afectada por consideraciones poblacionales, económicas, de equidad interterritorial $\mathrm{u}$ otras.

Este tipo de financiación tiene también venta- 
jas para la autonomía del ente descentralizado, porque lo recibido por cada territorio está directamente relacionado con su capacidad fiscal. Ello implica cierta responsabilidad del ente descentralizado frente a los votantes, y por lo tanto independencia con respecto a la administración central, sobre todo si las administraciones subnacionales intervienen en la gestión del tributo. Sin embargo, cabe señalar que no todos los tributos pueden ser distribuidos según criterios de territorialidad; y por lo demás, este tipo de financiamiento no resuelve los desequilibrios verticales y horizontales dentro del Estado y de hecho crea muchos problemas cuando es el único criterio utilizado para transferir ingresos a las unidades subnacionales.

La relevancia de esta cuestión fue muy evidente en México, país que había basado tradicionalmente su sistema de descentralización fiscal en la participación de carácter territorial en los impuestos estatales.

En ese país, mientras la recaudación tributaria estaba integrada básicamente por impuestos a la producción y al consumo, y la aportación de PEMEX era baja, el método de distribución tenía una base territorial, según el criterio de que cada entidad federativa debía recibir lo que había contribuido a crear. Sin embargo, la introducción del IVA - difícil de regionalizar-y el alza de los precios del petróleo, que benefició desproporcionadamente a unos estados más que a otros, dio lugar a una importante modificación en la que estuvieron presentes ideas de interdependencia de los estados subnacionales y de equidad. No obstante, se sigue manteniendo algún tipo de partici- pación territorial, y el artículo 2 de la Ley de Coordinación Fiscal de 1980 establece para los estados adheridos al Sistema de Coordinación Fiscal y que se encuentren coordinados en materia del impuesto sobre adquisición de inmuebles, una participación adicional al Fondo General de Participaciones (que equivale de hecho a compartir ingresos fiscales) y una participación del $80 \%$ de la recaudación que se obtenga en su territorio del impuesto sobre tenencia o uso de vehículos, cuando colaboren en la recaudación de dicho impuesto.

La Constitución de Brasil prevé también un mecanismo de participación territorial muy importante que afecta sobre todo a los municipios (art. 158), y que la Constitución diferencia perfectamente de las transferencias enunciadas en el art. 159 a las que nos referiremos más adelante. En efecto, a los municipios pertenece, entre otros, el 50\% del producto de la recaudación del impuesto de la Unión sobre la propiedad territorial rural correspondiente a los inmuebles situados en ellos; el $50 \%$ de la recaudación del impuesto del Estado sobre la propiedad de vehículos automotores que hayan obtenido su licencia en su territorio y $25 \%$ de la recaudacion del impuesto del Estado sobre operaciones relativas a circulación de mercancías y sobre prestaciones de servicio de transporte interestadual e intermunicipal, y de servicio de comunicación.

En Perú se prevé de esta misma manera entregar a las regiones una participación del impuesto nacional en función de la renta que produce la explotación de recursos naturales en ellas ubicados.

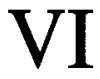

\section{Desequilibrios verticales y desequilibrios horizontales}

En todos los países más o menos descentralizados se produce lo que se denomina desequilibrio vertical, entendido como las divergencias que' pueden existir entre las fuentes de ingreso de los entes autónomos y sus necesidades de gasto. Ese desequilibrio fiscal se corrige mediante transferencias desde el gobierno central a los otros gobiernos territoriales y refleja la dependencia de estos últimos respecto del primero.

En efecto, la práctica demuestra que el volumen de ingresos percibidos directamente por los gobiernos subnacionales es insuficiente para financiar sus necesidades de gasto. Las subvenciones o transferencias tratan de compensar ese desequilibrio mediante una redistribución de los recursos fiscales disponibles en el conjunto de las administraciones públicas, canalizándolos desde las superiores hacia las inferiores, por entender que éstas, consideradas globalmente, se hallan en una situación de insuficiencia financiera (Castells, 1988, pp. 69-70).

El desequilibrio señalado obedece a dos razones: 
la falta de dinamismo de los ingresos propios de los gobiernos subnacionles, y las crecientes necesidades de gasto concentradas en esos niveles de gobierno. Por consiguiente, el problema del desequilibrio fiscal vertical dependerá en primer lugar de cuál sea la autonomía fiscal obtenida a través de ingresos propios de cada ente descentralizado y de cuál sea la asignación de competencias. Como es evidente, dicho desequilibrio será mayor en países como México, donde el gobierno federal basa sus ingresos en impuestos más elásticos - como son el de la renta y el que se aplica a las ventas- mientras que los estados federados basan sus ingresos propios en los impuestos prediales, y será menor en federaciones como la brasileña, en la que el impuesto sobre la ventas pertenece a los estados federados.

La segunda causa de este desequilibrio -es decir, las necesidades crecientes de gasto- se da en todos los países, pero su efecto dependerá de cuál haya sido la asignación de funciones. En este sentido, por ejem- plo, la escasa autonomía tributaria de los entes descentralizados mexicanos es manejada mediante la disminución de las obligaciones de los estados y municipios, ${ }^{5}$ por lo que los problemas que genera la descentralización fiscal se resuelven con una reducción de la descentratización administrativa.

Junto al problema de desequilibrio vertical aparece también uno de desequilibrio horizontal entre las unidades de gobierno de un mismo nivel (estados federados, regiones o municipios), debido a la falta de correspondencia entre su capacidad fiscal y sus necesidades de gasto. En efecto, no todas las unidades poseen la misma renta, o la misma capacidad fiscal, y hay que establecer entre ellas alguna forma de reequilibrio. Para ello se recurre a subvenciones o transferencias equiparadoras destinadas a que las más pobres puedan disponer de niveles de servicios comparables con los de las más ricas. A veces una misma transferencia puede tener por objeto corregir el desequilibrio vertical y el horizontal.

\section{VII}

\section{Las transferencias: modalidades y propósitos}

Decíamos que la forma de resolver los desequilibrios, tanto horizontales como verticales, pasa por las transferencias o subvenciones. Existen muchos tipos de ellas calificadas en función de diferentes criterios. La principal dificultad de dichas clasificaciones es que una misma transferencia puede incluirse en varias tipologías en función de los criterios elegidos.

Una primera clasificación podría realizarse de conformidad con los criterios seguidos para decidir la cuantía global. En este sentido, la cuantía de la subvención puede ser decidida como un porcentaje fijo de los ingresos centrales, cuando se trata de ingresos compartidos entre las administraciones. Este es el sistema de participación en los ingresos, caracterizado porque el importe de la subvención es un porcentaje de los ingresos del Estado. En Perú, por ejemplo, la ley $\mathrm{N}^{\circ} 25.193$ ( 30 de enero de 1991) preveía que para el año 1991 se transfiriera a los gobiernos regionales la totalidad de lo recaudado a nivel nacional por concepto de impuestos a la renta y patrimonio. Posteriormente, la Ley Anual de Presupuestos del Sector Público y Sistema Empresarial del Estado para 1991 (ley $\mathrm{N}^{\circ} 25.294$ del 15 de enero de 1991) precisa lo dispuesto en la ley anterior, de modo que la transfe- rencia a los gobiemos regionales de los impuestos a la renta se cumplirá en $50 \%$ en 1991 y el poder ejecutivo programará el $50 \%$ restante para el presupuesto de 1992. Este sería un ejemplo de transferencia a través de participación en los ingresos.

Dejando aparte los supuestos de distribución territorial (en cuyo caso estaremos en presencia, no ya de una subvención sino de un ingreso propio, que en la literatura recibe el nombre de participación en los impuestos y al que nos hemos referido en apartados precedentes), las subvenciones se clasifican atendiendo a si la transferencia se ha asignado sobre la base de una fórmula preestablecida, de manera điscrecional o para reembolsar determinados gastos. La distribución por fórmula es en principio más perfecta, porque se basa en criterios objetivos y mensurables y se utiliza mucho en mecanismos como el fondo común municipal de Brasil o el de Chile. Las transferencias discrecionales se utilizan sobre todo para proyectos de infraestructura en muchos países, y pueden basarse en evaluaciones técnicas y objetivas de proyectos

\footnotetext{
s Sobre México véase CEPAL, 1985.
} 
propuestos o en factores eminentemente políticos. No obstante, en algunos países se han utilizado transferencias discrecionales por no haberse resuelto problemas básicos de la distribución de ingresos del Estado. Este es el caso de los Aportes del Tesoro Nacional en Argentina, utilizados desde 1983, momento en que expiró la ley de coparticipación, hasta 1987 , año en que se dictó la nueva. En lo posible, es ideal diseñar mecanismos transparentes y rigurosos para otorgar la subvención.

Por último, hemos considerado como categoría independiente las subvenciones destinadas a reembolsar el importe de determinados gastos - como por ejemplo los que asumen los municipios al hacerse cargo de competencias nuevas como la salud o la educación-, aunque dicho importe puede ser determinado a través de una fórmula o de manera discrecional.

Otra clasificación importante es la que atiende a la condicionalidad o incondicionalidad de la subvención. Convencionalmente se divide a las subvenciones entre las de carácter general o incondicionales, y las condicionales, y estas últimas admiten múltiples clasificaciones en función del grado de condicionalidad. Las subvenciones incondicionales no establecen exigencia de tipo alguno a los gobiernos subnacionales sobre el uso de los fondos. Las transferencias condicionales, por el contrario, restringen el uso de los recursos a determinados sectores o a proyectos específicos, y pueden imponer además algunos otros requerimientos más o menos restrictivos, incluso dentro del sector o del proyecto. Por ejemplo, una subvención destinada al sector salud puede estar condicionada a que los fondos sean gastados en plazas de cama hospitalarias y obligar al gobierno subnacional a demostrar, para tener acceso a la subvención, que es capaz de otorgar un determinado nivel de prestación de servicios primarios de salud. Interés especial tienen las condiciones relacionadas con la recaudación tributa- ria. Argentina ofrece un buen ejemplo de este tipo de transferencias, ya que para que los gobiernos provinciales tengan derecho a compartir los ingresos deben preparar y poner en marcha un plan de acción financiero con el fin de evitar déficit fiscales. La reforma fiscal que actualmente está en discusión en Venezuela propone en este mismo sentido la coadministración de impuestos nacionales y particularmente del IVA, dejando a los estados la fiscalización de la recaudación y haciendo depender de su eficacia en este aspecto la cantidad de recursos que el gobierno nacional les transfiera por lo que produzcan.

Las subvenciones pueden también clasificarse en fijas o proporcionales, según que su cuantía se establezca como un importe fijo o bien como un porcentaje del gasto realizado por el gobierno subvencionado; esto último introduce una dimensión adicional - la participación de los gobiernos subnacionales en los costos- que puede estimular una mayor austeridad en la formulación del proyecto por parte del gobierno subnacional e incentivar su capacidad fiscal para obtener ingresos propios. Una posibilidad adicional es la de establecer la subvención con tope o sin tope.

Una última categoría que debe ser destacada es la que distingue entre subvenciones niveladoras de aquellas que no tienen esta finalidad. Las subvenciones niveladoras son las que tratan de corregir el desequilibrio fiscal horizontal entre administraciones descentralizadas del mismo tipo.

Todos estos tipos de clasificaciones proporcionan una gran variedad de instrumentos optativos para asignar recursos derivados de la combinación de una o más características, que tienen cada una su propia justificación teórica, sus ventajas y sus desventajas. Nos referiremos a algunas de ellas en relación a su utilización por algunos países de América Latina.

\section{VIII}

\section{Las participaciones en los ingresos}

Este título atiende solamente al origen de los ingresos de la subvención, pero no a la forma cómo ésta después se gasta. Las participaciones en los ingresos se consideran equivalentes a las subvenciones generales, por lo que una de las cuestiones más relevantes que plantea es la falta de vínculo entre la participación en el ingreso y el ingreso efectivamente generado por la jurisdicción de que se trate. En América Latina dichas participaciones tienen mucha importancia en los países federales, para financiar a los estados subnacionales a través de impuestos centrales, y en la financiación municipal.

El problema que tratan de resolver estas transferencias es el de la insuficiencia financiera de los go- 
biernos subnacionales, aunque a veces tambien responden a algunas consideraciones de equidad entre las diferentes jurisdicciones.

En realidad, todas las transferencias suponen de algún modo una participación en los ingresos de otra administracion, pero lo que caracteriza a las que incluimos en este epígrafe es que el monto de la transferencia es fijado como un determinado porcentaje de la recaudación de uno o varios impuestos y después es distribuido entre las jurisdicciones subnacionales sin tener en cuenta el esfuerzo fiscal de cada una, aunque puede establecerse algún incentivo en este sentido.

El sistema tiene su origen en un fondo establecido en 1966 en Estados Unidos: el gobierno federal reservaba un $2 \%$ de la recaudación efectiva del impuesto sobre la renta de las personas físicas (establecido sobre la base neta y no sobre la cuantía de la recaudación) para constituir un fondo que después se distribuía entre los estados con arreglo a la población respectiva. Desde el punto de vista teórico, se plantea un interesante problema al incluir o no este tipo de ingreso entre aquellos que contribuyen a la autonomía o dependencia del gobierno subnacional. En América Latina esto tiene diversas expresiones: a continuación nos referiremos a algunas de ellas.

En Brasil, la reciente Constitución establece en el artículo 159 un Fondo de Participación de los Estados formado por ingresos federales. Efectivamente, el gobierno federal ha de depositar el $21.5 \%$ de la recaudación del impuesto sobre la renta y del impuesto sobre productos industriales en dicho fondo de participación estadual, que es distribuido posteriormente por el Consejo de los Estados entre cada uno de ellos. Hay que hacer notar que el porcentaje se calcula sobre la recaudación efectiva de los impuestos (el resultado de aplicar el tipo de gravamen a la base neta) y no sobre la base misma. Para determinar la participación de cada estado en este fondo, se reserva un $85 \%$ de él para ser distribuido entre los estados del norte, nordeste y centro-oeste, y el $15 \%$ restante para los estados del sur y del sudeste. Esta primera distribución del fondo trata de salvaguardar los objetivos de equidad regional. La redistribución posterior se hace a través de una fórmula que tiene en cuenta la población de los estados y un indicador de capacidad fiscal consistente inversamente proporcional a su ingreso per cápita.

Además del Fondo, la Constitución establece otros dos tipos de participación en el ingreso federal.
Un 3\% de la recaudación de los mismos tributos anteriores se reserva para la aplicacion de programas de financiamiento al sector productivo de las regiones del norte, nordeste y centro-oeste a través de sus instituciones financieras de carácter regional, de conformidad con los planes regionales de desarrollo. $Y$ un $10 \%$ de la recaudación sobre productos industrializados se entrega a los estados y al Distrito Federal en proporcion al valor de sus respectivas exportaciones de productos industrializados.

Por último, la Constitución brasileña establece un Fondo de Participación Municipal de características muy similares al establecido para los estados, generado por un $22.5 \%$ de la recaudación del impuesto sobre la renta y el impuesto sobre productos industriales, y que ha de ser distribuido a los municipios teniendo en cuenta su población y su ingreso per cápita.

Una naturaleza parecida tienen el situado constitucional en Colombia y Venezuela y el Fondo General de Participaciones en México, aunque en estos casos la participación no se establece sobre determinados tributos sino sobre el total de los ingresos.

En Colombia, el llamado "situado fiscal", establecido constitucionalmente y recientemente modificado, establece un porcentaje mínimo de los ingresos corrientes de la nacion que ha de ser transferido a los gobiernos seccionales (Departamentos), con una destinación a gastos de educación y salud. Los nuevos criterios para su distribución son, entre otros, la población afectada, los objetivos y necesidades básicas en esos servicios, y la eficacia administrativa y el esfuerzo fiscal de estas entidades. Tales criterios también han sido recogidos por la nueva Constitución y las propuestas de reglamentación establecen además la posibilidad de que los servicios de salud y educación se descentralicen hasta el nivel municipal.

En Venezuela se conoce con el nombre de "situado" una partida especial incluida en el presupuesto por mandato constitucional que se distribuirá entre los estados, el Distrito Federal y los territorios federales "en la forma siguiente: $30 \%$ de dicho porcentaje por partes iguales, y el $70 \%$ restante en proporción a la población de cada una de las citadas entidades. Esta partida no será menor del $12.5 \%$ del total de ingresos ordinarios estimados en el respectivo presupuesto... La ley orgánica respectiva determinará la participación que corresponda a las entidades municipales en el situado" (art. 229 de la Constitución). 
Las recientes reformas efectuadas en Venezuela con el fin de acrecentar la descentralización política, administrativa y fiscal han introducido importantes modificaciones en este tema. La Ley Orgánica de Descentralización, Delimitación y Transferencia de Competencias del Poder Público, aprobada en diciembre de 1989, derogó la anterior Ley de Coordinación del Situado y recogió planteamientos más equitativos para su distribución mediante las siguientes disposiciones: i) el situado pasará a constituir una partida del $16 \%$ del total de ingresos ordinarios estimados en el presupuesto; tal porcentaje se incrementará anual y consecutivamente en $1 \%$ hasta alcanzar al $20 \%$ anual; ii) en las leyes de presupuestos de los estados se incorporará una partida destinada a las municipalidades, denominada situado municipal, que para 1990 será del $10 \%$ del total de los ingresos ordinarios. Tal porcentaje se incrementará anualmente hasta llegar al $20 \%$ y se distribuirá de acuerdo a lo previsto en la Ley Orgánica de Régimen Municipal.

México había tenido tradicionalmente un sistema de participación impositiva basado en la recaudación obtenida por cada entidad, el que fue modificado por la Ley de Coordinación Fiscal de 1980. La exposición de motivos de dicha ley aclara así la modificación introducida: "las participaciones no se otorgarán en función de las recaudaciones que se obtengan en cada entidad, sino que se llevarán a un Fondo General de Participaciones, con cargo a todos los impuestos federales, el cual se distribuirá entre las entidades en los términos de una nueva Ley de Coordinación Fiscal y de los convenios que las entidades que así lo deseen, celebren con la Federación. En dichos convenios se señalarán también las facultades para administrar el impuesto que ejercerán las entidades federativas".

El nuevo sistema se basa principalmente en dos acuerdos concertados entre los estados y la federación: el Convenio de Adhesión al Sistema de Coordinación Fiscal y el Convenio de Colaboración Administrativa. Para el funcionamiento del sistema se establecieron tres fondos: el Fondo General de Participaciones, el Fondo Financiero Complementario y el Fondo de Fomento Municipal (CEPAL, 1985).
El Fondo General de Participaciones está constituido por el 13\% de los ingresos totales anuales que obtiene la federación por concepto de impuestos y derechos sobre los hidrocarburos, la extracción de gas natural y la minería. Para los fines del reparto sólo se tiene en cuenta la recaudación efectiva. En la distribución del fondo, cada estado tiene asegurada una cantidad igual a la que le hubiera correspondido en el año anterior, y además un incremento calculado conforme a una fórmula que tiene en cuenta el esfuerzo recaudatorio de los impuestos federales en cada estado. Esta fórmula particular, que incorpora una calificación del esfuerzo fiscal del Estado para determinar la cuantía de la transferencia, permite en alguna medida estrechar la disparidad que entre ingresos y gastos se produce con las participaciones y tiene importancia no solamente económica, sino también política al acrecentar la responsabilidad fiscal de los gobiernos subnacionales.

Se establece además un Fondo Financiero Complementario constituido por el $0.50 \%$ de los ingresos totales anuales que obtenga la federación por concepto de impuestos y derechos sobre hidrocarburos, el 3\% del Fondo General de Participaciones y otra cantidad igual con cargo a la federación. Dicho Fondo es distribuido en proporción inversa a la participación por habitante que tenga cada entidad en el Fondo General de Participaciones.

Por último, se crea un Fondo de Fomento Municipal formado sobre la base de diferentes tipos de ingresos, que es distribuido en primer lugar a los estados, con reglas similares a las del Fondo General de Participaciones, y que éstos después distribuyen entre sus municipios de acuerdo a lo que establezcan las legislaturas locales.

En Argentina la nueva Ley de Coparticipación Federal, vigente desde 1988, prevé una primera distribución de los recursos coparticipados de $42.34 \%$ al gobierno central y $57.66 \%$ a los gobiernos provinciales. Los ingresos compartidos son el IVA, los de ganancias, capitales, combustibles y otros menores. La distribución posterior entre provincias tiene en cuenta criterios territoriales más que poblacionales, pero prevé mayores transferencias a las áreas en que se concentran más familias pobres. 


\section{IX}

\section{Transferencias destinadas a reembolsar el}

\section{importe de determinados gastos}

Otras transferencias que tienen mucha importancia en América Latina son aquellas destinadas a reembolsar el importe de determinados gastos. La fórmula es muy útil, sobre todo en los inicios de los procesos de descentralización, porque permite que se transfiera una determinada competencia a un nivel subnacional, traspasándole al mismo tiempo los recursos necesarios para hacer frente a ella, lo que en principio permite equilibrar a la vez el presupuesto nacional -que se desprende de la competencia a la vez que transfiere los recursos- y el del ente descentralizado.

Este es, por ejemplo, el procedimiento previsto en la Ley de Descentralización venezolana de 1989, que contempla el traspaso de cada competencia junto con el de la asignación presupuestaria que el gobierno central dedica a la prestación del servicio en cuestión. Un procedimiento similar se ha utilizado con relativo éxito en Chile para el traspaso a los municipios de determinadas competencias en materia de salud y educación (Castañeda, 1990).

En Chile, en el sector de educación, se iniciaron en 1980 importantes reformas que preveían, entre otras modificaciones, la transferencia de escuelas de los niveles preescolar, primario y secundario a las municipalidades. Para ello se transfirió la infraestructura de las escuelas a las municipalidades con arreglo a un convenio especial denominado comodato. El dinero para pagar a los profesores fue transferido desde el Ministerio de Educación a las municipalidades; además, ese ministerio subvenciona a las municipalidades para los gastos de educacion, calculados éstos por una fórmula fijada en función de cada estudiante matriculado. En materia de salud, en 1981 se inició igualmente el traspaso de los centros y consultotios de salud a las municipalidades con un mecanismo de financiamiento consistente en el pago a las municipalidades de la atención prestada, a través de un sistema de Facturación por Atención Prestada por las Municipalidades (FAPEM). El FAPEM es un sistema de pago anticipado y de reembolso que incluye quince categorías de servicios de atención primaria, cada una de las cuales tiene un valor que cubre los gastos por concepto de bienes y servicios, personal y mantención.

Un sistema parecido se estableció en Brasil para el sistema de salud, aunque a nivel estadual; pero, a diferencia del anterior, la cuantía de la subvención no es fijada a través de una fórmula, sino por convenio. Recientemente se creó en ese país un Sistema Unico de Salud (SUS), con la transferencia a los estados y municipios de las unidades básicas y los hospitales regionales, así como de los médicos y funcionarios del sistema (aunque éstos siguen pagados por el gobierno federal). La distribución de los recursos del SUS se efectúa a través de un sistema de planificación integrada, que hace una estimación de las necesidades para cubrir la atención médica y las inversiones en cada distrito sanitario. La estimación se realiza sobre la base de un perfil epidemiológico del distrito, el número de internamientos o consultas médicas del año anterior, la red física instalada (pública o privada) y otras variables. Los planes de los distritos sanitarios son consolidados en cada estado que prepara su plan de acción, y enviados a la dirección del SUS nacional. Los montos asignados a cada estado se deciden en reuniones entre los secretarios estaduales y el Ministerio de Salud (Brakarz, 1991).

Este tipo de transferencias se caracteriza por una gran dependencia de la administración central y por su alto grado de condicionalidad, ya que los fondos recibidos han de destinarse al uso previsto. 


\section{X}

\section{Transferencias nivelatorias o perecuatorias}

Aunque algunas transferencias por participación en los ingresos suelen incluir entre sus motivaciones algunas consideraciones de equidad, la mayoría de los sistemas de financiación de entes descentralizados establecen algún tipo de transferencia especial para que los entes más ricos transfieran recursos a los más pobres, con la finalidad de asegurar un nivel mínimo de servicios públicos y de solidaridad entre los diferentes espacios territoriales de la nación. Aunque algunos de estos objetivos pueden ser previstos en mecanismos como los de participación en los ingresos, no se descarta establecer transferencias adicionales con este propósito. En Venezuela, por ejemplo, las reformas sobre previsión fiscal incluyen no solamente la reforma del situado constitucional, sino también la creación de un Fondo de Solidaridad Interregional.

Los criterios para establecer este tipo de transferencias son muy variables, pero básicamente apuntan a extraer recursos de las administraciones más ricas para entregarlos a las más pobres.

El Fondo Común Municipal en Chile participa de estas características, pues supone una importante transferencia desde las comunas más ricas y del presupuesto estatal a las comunas más pobres, para las cuales de hecho constituye principal fuente de financiación.

Este Fondo está compuesto por los siguientes recursos (DL 3063 Ley de Rentas Municipales):

i) $60 \%$ del impuesto territorial recaudado en

\section{XI}

\section{Conclusiones}

El tema de la descentralización físcal, o el de la financiación de las administraciones subnacionales, tiene carácter de instrumental con respecto a la descentralización. Esta requiere decisiones políticas y administrativas acerca de cuál va a ser la organización del Estado y de la administración pública de un país; una vez iniciado el proceso, o al menos una vez diseñado el modelo de organización pública, el cada comuna (el $40 \%$ restante queda entre los recursos propios de la comuna del contribuyente).

ii) El aporte fiscal que determine la ley de presupuesto del sector público.

iii) $50 \%$ de lo recaudado por permisos de circulación de vehículos.

iv) $45 \%$ de lo recaudado por patentes comerciales en la comuna de Santiago.

v) $65 \%$ de lo recaudado por patentes comerciales en las comunas de Providencia y Las Condes.

Los recursos del Fondo se distribuyen entre las comunas del país de acuerdo a los siguientes criterios:

i) $10 \%$ en proporción directa al número de comunas.

ii) $20 \%$ en proporción directa a la población de cada comuna.

iii) $30 \%$ en proporción directa al número de predios exentos del impuesto territorial de cada comuna.

iv) $40 \%$ en proporción directa al menor ingreso propio permanente por habitante de cada comuna, en relación al promedio nacional de dicho ingreso por habitante.

La ley señala además que las municipalidades deben destinar los recursos procedentes de este Fondo preferentemente a crear, mantener y prestar servicios a la comunidad local. financiamiento de la descentralización adquiere gran trascendencia, pues habrá que resolver cómo las administraciones descentralizadas han de financiar las competencias transferidas. La descentralización política y la administrativa pueden fracasar si no van acompañadas de un proceso paralelo de descentralización fiscal. Por otra parte, la descentralización es a veces justificada por motivos financieros, como el 
de eficiencia en la asignación de los recursos públicos dentro del Estado, de modo que debe ser estudiada y analizada al examinarse los temas políticos y administrativos.

No existe una correspondencia exacta entre la descentralización administrativa de funciones y la autonomía fiscal en el sentido de que las competencias transferidas tengan que financiarse con recursos de las administraciones subnacionales. La relación entre una y otra dependerá desde luego del propio proceso de descentralización. No obstante, la falta absoluta de sincronización entre una y otra pone en peligro la viabilidad del proceso descentralizador en su conjunto, ya que la inexistencia de autonomía fiscal conlleva en alguna medida una menor autonomía política y administrativa. La madurez de un sistema descentralizado de competencias administrativas exigirá un alto grado de autonomía fiscal.

Para los efectos de la autonomía del ente descentralizado habrá que tener en cuenta no solamente la capacidad de éste de financiarse con ingresos propios, sino también la de decidir acerca del gasto realizado con ingresos procedentes del Estado. Hay diferentes tipos de ingresos del ente subnacional que proceden de la administración central. En general el ente s6lo es autónomo, desde el punto de vista del gasto que realiza, cuando se financia con recursos propios o cuando lo que recibe corresponde a participaciones en los ingresos del Estado o a transferencias automáticas, predecibles y no condicionadas.

La financiación de los entes descentralizados basada en un sistema de imposición propio resulta siempre muy reducida en América Latina, donde por el contrario existe un alto grado de dependencia financiera, ya que los recursos se obtienen en su mayor parte del ente central. La dependencia será mayor o menor según las características de la fuente financiera. En general, la no financiación con recursos propios hace que los gobiernos subnacionales caigan fá- cilmente en la irresponsabilidad fiscal, ya que no soportan el costo político de establecer tributos, y que la administración central tienda a que esa dependencia sea alta, tratando de controlar a la administración subnacional a través del otorgamiento de transferencias condicionadas a ciertos gastos.

En todo caso, las transferencias desde la administración central son siempre necesarias porque la financiación con recursos propios en todo o en parte genera desequilibrios, bien por la diferencia entre las fuentes de ingreso de los gobiernos autónomos y sus necesidades de gasto (desequilibrios verticales), bien porque entre las unidades de gobierno de un mismo nivel no se corresponde su capacidad de ingreso y de gasto (desequilibrio horizontal).

Entre los ingresos propios, entendidos como aquellos establecidos por el ente subnacional en su propio territorio en forma paralela o complementaria a los tributos nacionales, y las transferencias condicionadas, que son aquéllas en que la administración central toma decisiones importantes sobre el nismo gasto, existe una amplia gama de instrumentos de financiación. Estos tienen importantes efectos en las administraciones subnacionales y todos ellos son utilizados en América Latina con diferentes finalidades, de modo que en cada país el sistema aplicado es una especie de mixtura de varias formas de financiación. Entre tales instrumentos se encuentran, por ejemplo, los rendimientos de impuestos estatales que son percibidos por el ente subnacional según criterios de territorialidad (y por lo tanto según su capacidad fiscal), lo que refuerza la autonomía fiscal del ente; las participaciones en impuestos por conceptos distintos de la territorialidad, que resuelven de manera eficiente el tema de los desequilibrios aunque desvinculan el origen del ingreso del gasto realizado, y las transferencias de distinto tipo, condicionadas o no, destinadas también a financiar los desequilibrios, pero que permiten un mayor control de la administración central.

\section{Bibliografia}

Banco Mundial (1988): Informe sobre el desarrollo mundial 1988, Washington, D.C.

(1990): Argentina. Provincial Govermment Finances, Washington, D.C.

Brakarz, J. (1991): Aspectos institucionales de la descentralización. Soluciones gerenciales y modelos innovadores de organización de funciones públicas en Latinoamérica, trabajo presentado al seminario internacional Descentralización $y$ Desarrollo en América Latina, Santa Cruz, Bolivia, diciembre, mimeo.
Campbell, T. (1991): Descentralización hacia los gobiernos locales en los países latinoamericanos: estrategias nacionales y respuesta local en la planificación, gastos y administración, Informe, $N^{\circ} 5$, Departamento Técnico para América Latina y el Caribe, julio.

Castanteda. T. (1990): Para combatir la pobreza: politica social y descentralización en Chile durante los '80, Santiago de Chile, Centro de Estudios Públicos (CEP).

Castells, A. (1988): Hacienda autonomica. Una perspectiva de federalismo fiscal, Ariel. 
(1991): Suficiencia, autonomía y equidad, El país, Madrid, 5 de noviembre.

CEPAL (Comisión Económica para América Latina y el Caribe) (1985): Las relaciones tributarias entre los diversos niveles de gobierno de un sistema federal. El caso de México (LC/ MEX/R.7), Santiago de Chile, 29 de marzo.

CLAD (Centro Latinoamericano de Administración para el Desarrollo) (1991): Proceso de descentralización en Venezuela, Reporte de avances, Caracas, CLAD, julio.

De la Cruz, Rafael (1989): La descentralización en Venezuela: un reto para la gestión del Estado. Antecedentes y perspectivas, documento de la COPRE (Comisión Presidencial para la Reforma del Estado (Venezuela)/PNUD (Programa de las Naciones Unidas para el Desarrollo), Proy.VEN/89/ 501.
Giménez, A. (1979): Introducción, Financiación de las autonomias, Madrid, Blume.

Morgan, M.T. (1991): Panorámica conceptual de la descentralización, trabajo presentado al seminario internacional Descentralización y Desarrollo en América Latina, Santa Cruz, Bolivia, diciembre, mimeo.

Musgrave, R. (1991): The Theory of Public Finance, Nueva York, McGraw Hill.

Sevilla Segura, José (1991): La financiación de las comunidades autónomas. El problema, El país, Madrid, 3 de octubre.

Shah, Anwar (1990): The New Fiscal Federalism in Brazil, Policy, Research, and External Affairs Working Papers, $N^{\circ} 557$, Washington, D.C., Banco Mundial, diciembre.

Suárez Pandello, J. (1988): Experiencias internacionales de financiación local, Madrid, MAP. 